\title{
Long-Range Regulation of Cytokine Gene Expression
}

\author{
Emily Rowell ${ }^{1}$, Matthias Merkenschlager ${ }^{2}$, and Christopher B. Wilson ${ }^{1}$ \\ 1Department of Immunology, University of Washington, Seattle, WA 98195, USA \\ 2Lymphocyte Development Group, MRC Clinical Sciences Centre, Imperial College, London, Du Cane Road, \\ London W12 ONN, UK
}

\begin{abstract}
In metazoans, transcription is regulated by promoters and additional elements, which may be located far from their target gene(s). Moreover, genes (including those encoding cytokines and cytokine receptors) are commonly clustered in the genome, providing the opportunity for the shared, competitive or sequential use of regulatory elements. New techniques, discussed here, are generating an avalanche of high-resolution genome-wide data through which candidate regulatory elements have been identified in specific cell types (including $\mathrm{T}$ cells), their functions inferred, and their physical interactions in 3-dimensional space demonstrated. As a result, a nearly comprehensive list of regulatory elements in the Th2 cytokine locus, a growing list of elements in the interferon- $\gamma$ gene locus, and maps of their 3-dimensional interactions are now available, though much remains to be learned about the molecular mechanisms at play, the dynamics of these interactions and their functional importance.
\end{abstract}

\section{Introduction}

Effector T lymphocytes are characterized by the cytokines they produce and the effector functions they exert. Th1 cells produce IFN- $\gamma$ as their signature cytokine and are important for host defense to intracellular pathogens, Th2 cells produce the cytokines IL-4, IL-5 and IL-13 and protect against helminths, whereas cells of the more recently identified Th17 lineage produce IL-17a, IL-17f, IL-21, and IL-22 and provide immunity against extracellular bacterial and fungal pathogens for which Th1 or Th2 cells are not sufficiently protective. By contrast to these protective functions, Th2 cells orchestrate allergic responses, while Th17 and Th1 cells are involved in autoimmune diseases.

Th1 development is specified by the cytokines IL-12 and IFN- $\gamma$, which signal through the transcription factors (TFs) STAT4 and STAT1 and induce the Th1 'master regulator' TF Tbet, whereas IL-4 instructs Th2 commitment, signaling via STAT6 and inducing the Th2 'master regulator' TF GATA-3. In the past two years, Runx3 and Runx 1 have been shown to collaborate with T-bet to augment IFN- $\gamma$ expression, silence IL-4 expression and reinforce Th1 lineage commitment $(1,2)$. At the same time, work from several groups has shown that IL-6 and TGF- $\beta$ initiate Th17 differentiation via STAT3, the orphan nuclear receptor ROR $\gamma(\mathrm{t})$ and its paralog ROR $\alpha$ (3), inducing these cells to produce IL-21, which acts in an obligatory and autocrine manner to reinforce the Th17 fate, while IL-23 produced by antigen presenting cells sustains expression of these TFs and Th17 survival and cytokine secretion thereafter.

But where and how do these TFs act? TFs control cytokine expression in part by binding to and recruiting RNA polymerase II containing complexes to gene promoters, but promoters 
alone are insufficient for proper lineage-specific cytokine expression. Additional and often quite distal regulatory elements are required for proper expression, as Agarwal and Rao discussed in their review of cytokine gene expression, which appeared in this journal ten years ago (4). Work done subsequently has sought to identify the complete set of regulatory elements in cytokine gene loci and to assess their contribution to cytokine gene expression in vitro and in vivo. The current review discusses this work, focusing in particular on the last several years. During this time, technological innovations have permitted distal regulatory elements to be mapped more comprehensively and more globally, yielding an increasing more complete view of the true dimensions of cytokine gene loci, the numbers of regulatory elements within, and the dynamic evolution of their epigenetic marks and physical and functional relationships in response to environmental cues and $\mathrm{T}$ cell differentiation.

\section{Regulatory elements and how to identify them}

Eukaryotic promoters are located directly upstream of the transcribed region, providing a site for recruitment of RNA polymerases and subsequent initiation of transcription. Promoterdriven transcription is influenced by cis-regulatory elements - sequences located on the same chromosome anywhere from a few $\mathrm{kb}$ to tens or hundreds of $\mathrm{kb}$ from the gene(s) they help to regulate. Cis-regulatory elements that modulate gene expression include enhancers, silencers, locus control regions (LCRs), insulator/boundary elements and matrix attachment regions (MARs). Enhancers greatly increase the basal level of gene transcription regardless of their orientation and location upstream, downstream or even within introns. In contrast, silencers repress expression, either actively or in a 'hit-and-run' fashion by inducing the formation of heritable alterations to chromatin (5). LCRs contain both enhancer and insulator activity and are defined as cis-regulatory elements conferring tissue-specific, copy-number-dependent gene expression (6). Insulators/boundary elements may demarcate genomic loci and establish or maintain the organization of chromatin into domains that allow genes to be regulated independently of the influence of neighboring loci (7). Some insulators function as barriers protecting a genomic locus from silencing by surrounding heterochromatin - while others block the activity of neighboring enhancers. MARs are thought of as sequences through which chromatin loops are tethered - perhaps to the nuclear matrix (8).

Gene expression is governed by these regulatory elements through the binding of TFs and other regulatory proteins, with the probability of binding determined by factor abundance and ability to access target regulatory elements in chromatin. Chromatin accessibility at regulatory elements is influenced by nucleosome composition, position and interactions with DNA, posttranslational histone modifications, and methylation of cytosines within $\mathrm{CpG}$ dinucleotides. Such modifications also serve as landmarks for the presence and activity of regulatory elements in a given cell type $(9-10,11 \bullet)$ and techniques for their detection are essential tools for finding candidate regulatory elements. Regulatory elements often show evolutionary conservation, which means that they may be predicted by computational searches for evolutionarily conserved non-coding sequences (CNSs) (Box 1).

Nucleosomes are typically displaced or altered in conformation at functional regulatory elements, thereby rendering the DNA at these sites hypersensitive to digestion by DNase I. Thus, DNase hypersensitive (HS) sites denote the presence of regulatory elements functional in the cell type studied (12). Patterns of histone modifications, DNA methylation and binding of specific transcription and regulatory factors, when correlated to gene expression patterns in specific cell types, provide additional information by which the function of specific elements may be inferred. Technological advances have markedly accelerated element discovery, by providing high-resolution, genome-wide profiles of epigenetic marks in embryonic stem cells and certain differentiated cell types, including primary human CD4 T cells $(12,13 \bullet \bullet, 14-15$, 16•,17-18,19•). 
Chromatin immunoprecipitation (ChIP) paired with genome tiling arrays (Chip-chip) or highthroughput sequencing (ChIP-seq) has revealed that in active or poised genes histone $\mathrm{H} 3$ monoor di-methylated on lysine $4\left(\mathrm{H} 3-\mathrm{K} 4{ }^{\mathrm{me} 1}\right.$ or $\left.\mathrm{H} 3-\mathrm{K} 4^{\mathrm{me} 2}\right)$ marks the transcriptionally permissive chromatin of distal regulatory elements, transcribed regions and promoters (Figure 1); H3$\mathrm{K} 4^{\mathrm{me} 3}$ is markedly enriched on nucleosomes flanking the transcription start site; H2A.Z (a variant of $\mathrm{H} 2 \mathrm{~A}$ ) is present at promoters and distal regulatory elements but not within transcribed regions; RNA polymerase II (Pol II) and TAF1 are bound to transcription start sites and nucleosomes are displaced from them (20); DNase HS sites, detected using DNase-chip or DNase-seq, are found at the promoters and at intronic and distal regulatory elements of genes with these permissive chromatin marks $(11 \bullet, 19 \bullet)$; these marks and Pol II binding are most intense at actively transcribed genes, are commonly detected though less intense at primed and poised 'bivalent' genes, but are not detected at poised 'null' and silenced genes (see below and Figure 1). H3-K4 ${ }^{\mathrm{me} 3}$ coordinates proper transcription initiation by docking TFIID, CHD1, BPTF/NURF and MLL complexes, which in turn facilitate chromatin remodeling, transcript elongation, splicing and histone acetylation, sustain $\mathrm{H} 3-\mathrm{K} 4$ methylation, and remove repressive $\mathrm{H} 3-\mathrm{K} 9$ and H3-K27 methylation (20-22). H3-K36 ${ }^{\mathrm{me} 3}$ is present throughout the transcribed region of genes undergoing active transcription. Thus, focal $\mathrm{H} 3-\mathrm{K} 4{ }^{\mathrm{me} 3}$ followed by a region of H3-K36 ${ }^{\mathrm{me} 3}$ identifies active promoters and their transcribed regions with the magnitude of these marks correlating directly with transcription. Conversely, H3-K27me3 is not present in genes marked by $\mathrm{H} 3-\mathrm{K} 36^{\mathrm{me} 3}$, but rather at silent genes, consistent with its role in Polycombmediated repression (23). $\mathrm{H} 3 \mathrm{~K} 9^{\mathrm{me}} 3 / 2$ is an alternative mark associated with the silent heterochromatin associated with repetitive elements and transposons. However, discrete peaks of $\mathrm{H} 3 \mathrm{~K} 9^{\mathrm{me} 3 / 2}$ are present in some active genes where they are thought, like $\mathrm{H} 3-\mathrm{K} 36^{\mathrm{me}} 3$, to inhibit inappropriate transcription initiation (24). In contrast to the repressive nature of H3$\mathrm{K} 27^{\mathrm{me} 3 / 2}$ and $\mathrm{H} 3 \mathrm{~K} 9^{\mathrm{me} 3 / 2}$, H3K27 ${ }^{\mathrm{me} 1} \mathrm{H} 3 \mathrm{~K} 9^{\mathrm{me} 1}$ are found at active genes. Promoters of some genes are 'bivalent' - marked both by H3-K4 ${ }^{\mathrm{me} 3}$ and H3-K27 ${ }^{\mathrm{me} 3}(13 \bullet \bullet, 16 \bullet, 25)$. 'Bivalent' marks are most commonly found at $\mathrm{CpG}$ rich promoters of developmentally regulated genes that are inactive but poised for induction or silencing on differentiation, suggesting that lack of expression in this context is an active process. By contrast, $\mathrm{CpG}$ poor promoters of tissuespecific genes that are rapidly and transiently activated in response to environmental stimuli, i.e., immune response genes, often have neither mark in precursors but gain $\mathrm{H} 3-\mathrm{K} 4{ }^{\mathrm{me} 3}$ or $\mathrm{H} 3$ $\mathrm{K} 27^{\mathrm{me} 3}$ as they differentiate into expressing or non-expressing cell types, respectively (13•, $16 \cdot, 25)$. Boundary elements are suggested by the presence of an HS site separating a domain of accessible chromatin from repressive chromatin, where CCCTC-binding factor (CTCF) and cohesin mark and create chromatin domain boundaries $(13 \bullet \bullet, 16 \bullet, 19 \bullet, 25-26,27 \bullet)$. However, CTCF and cohesin may also bind within transcribed regions, and at these sites their binding does not necessarily impede transcription and chromatin remodeling, as is the case for a binding site in the first intron of Ifng, for reasons as yet unclear $\left(26^{\bullet}, 27 \bullet\right)$. Though not defined by such global studies, silencers may have 'bivalent' marks that resolve with further differentiation, as shown for the Il4 silencer (28).

\section{Linear clustering of genes and co-ordinate gene regulation}

In organisms from $S$. cerevisiae to humans, gene organization is non-random, in that coregulated genes are frequently located in linear proximity on the same chromosome (29-31). In some cases these clusters arose through gene duplication, which is an important substrate for evolutionary change because one copy is free to acquire coding and/or regulatory mutations that if advantageous will be positively selected and if deleterious will be lost. Examples include the $\beta$-globin, Hox, immunoglobulin, T cell receptor and MHC/HLA loci. In other cases, genes related in function but not in sequence are clustered, e.g., imprinted genes, genes in a specific metabolic pathway or whose expression is restricted to a particular cell type. Regardless of origin, evolutionarily conserved gene clusters are likely to be advantageous. Clustering may allow common regulatory elements or particular TFs to be shared, facilitate alternative or serial 
expression or serial rearrangement of genes through competition for regulatory elements, coordinate remodeling of chromatin, position as yet inactive developmental or environmentallyinduced genes in accessible chromatin associated with nearby housekeeping genes, or facilitate formation of chromatin loops and their approximation to transcriptional hubs.

\section{The Th2 Cytokine Locus}

Many cytokine and cytokine receptor genes are clustered. The best-characterized of these is the evolutionarily conserved Th2 cytokine locus, containing Il4, Il5, Ill3, and two housekeeping genes, Rad50 and Kif3a (Figure 2). This locus contains an array of known cisregulatory elements, including enhancers (Ill3 HS1,2; Il4 HSII/III; CNS1/HSS1,2; CNS2/ HSV, $\mathrm{V}_{\mathrm{A}}$ ), a silencer (II4 HSIV) and an LCR located in Rad50 introns (RHS 4-7) (32). These elements collaborate to assure proper Th2 cytokine expression, which appears to be dependent on their being approximated to each other through intrachromsomal looping (33). In a variety of cell types - even those that do not have the potential to express these cytokines - the Ill3 and $I l 5$ promoters are approximated to the Il4 promoter, creating a 'pre-poised' conformation. In naïve, Th1 and Th2 CD4 T cells and NK cells but not in B cells and fibroblasts these promoters are drawn more closely together and approximated to CNS1 and CNS2, and the Th2 LCR is approximated to the Il4 and Ill3 promoters, creating a 'poised' conformation. This conformation is dependent on STAT6 and the LCR and can be induced in fibroblasts by enforced expression of GATA3 in concert with $\mathrm{Ca}^{++}$-signaling. As there are few changes in conformation unique to Th2 cells, what allows for Th2 lineage-specific transcription of this locus? One possible answer is the restricted availability of STAT6 and GATA3. A second candidate is SATB1, which organizes the genome in a cell-specific manner by anchoring DNA to the nuclear matrix (8). In Th2 cells, activation upregulates SATB1, which then binds to CNS1, CNS2 and 9 other sites extending from Il5 past Kif3a, driving the formation of additional, smaller loops (34•). Knockdown of SATB1 prevents formation of this 'active' locus confirmation and markedly impairs $I l 4, I l 5$, and $I l l 3$ expression. These findings demonstrate an important role for SATB1-induced loop formation in Th2 cytokine expression and suggest that a Th2 chromatin domain extends to include Kif3a. Genome-wide analysis of human CD4 $\mathrm{T}$ cells has shown that CTCF binds between IL5 and its neighbor IRFI and between KIF3a and its neighbor $S E P T 8(13 \bullet \bullet)$, perhaps helping to segregate a Th2 domain from surrounding regions; consistent with this notion, DNase HS sites that differ in presence or magnitude between human Th1 and Th2 cells are evident throughout this region (authors' unpublished observations). The genes encoding IL-3 and GM-CSF are $\sim 500 \mathrm{~kb}$ downstream of Il5 and can be co-expressed by Th2 cells and eosinophils, raising the possibility of even more extended intrachromosomal interactions.

\section{The lfng-(IL26)-II22 locus}

While less well characterized than the Th2 locus, recent studies have identified multiple cisregulatory elements within $\sim 110 \mathrm{~kb}$ surrounding Ifng $(35-37,38 \bullet, 39)$, including enhancers and boundary elements many of which bind the Th1-TFs T-bet and STAT4 (Figure 2). Of these, IfngCNS-22 is an enhancer marked by permissive histone modifications in naïve, Th1 and Th2 CD4 T cells, suggesting that it may poise this gene for induction in the early stages of Th1 differentiation $(36,38 \bullet$ ). By contrast, IfngCNS+46 has insulator activity in vitro (38•), which might limit effects of potentially repressive downstream regions in Th1 cells and/or orchestrate spreading of repressive H3-K27 ${ }^{\text {me3 }}$ modifications in Th2 cells. The IfngCNS-6 (previously referred to as CNS1) enhancer is approximated to the Ifng promoter in naïve, Th1 and Th2 cells (33), although whether this reflects approximation through looping or merely linear proximity on the chromosome is unclear, while IfngCNS+18/20 (CNS2) is approximated to the Ifng promoter only in Th1 cells, presumably through looping (33). Additional loops approximate other distal elements to the Ifng promoter, some of which are common - perhaps representing a basal 'poised conformation', whereas others differ between Th1 and Th2 cells 
(authors' unpublished observations). The factors driving looping in the Th1 locus are unknown, but may include T-bet and STAT4. SATB 1 is expressed by human naïve, Th1 and Th2 cells, but is most highly expressed by Th2 cells (40), suggesting that other architectural proteins may be at work in Ifng locus organization.

Unlike the Th2 locus in which the three cytokine genes are co-expressed and likely arose through gene duplication, the nearest neighbors of Ifng are two members (IL26 and IL22) of the IL-1o family (38•), which are expressed predominantly by Th17 rather than Th1 cells (41-46); a housekeeping gene MDM1, lies further upstream (Figure 2). These genomic relationships are conserved from bony fish to humans, with the exception of rodents, in which Il26 has been lost; in some mouse strains, the position occupied by IL26 in humans instead contains an inverted and non-expressed duplication of Il22 (Iltifb) (38•). Although Ifng and Il22 (and IL26 in humans) are typically expressed by different T effector subsets, they can be co-expressed by $\mathrm{T}$ and NK cells in humans and mice (43-45). Yet unanswered is whether TFs critical for driving expression of Ifng or Il22 shut off one another through active repression or by altering chromatin conformation, or whether chromatin loops promote competition between these genes for shared regulatory elements in some contexts while facilitating their coordinate expression in others.

\section{Other cytokine gene clusters}

There are a number of other evolutionarily conserved cytokine and cytokine receptor gene clusters. One cluster contains the other four members of the IL-10 family - IL10, IL19, IL20, and IL24. Originally considered to be a Th2 cytokine, IL-10 can be produced by all types of CD4 effectors and by CD8 T cells, macrophages, and B, mast and dendritic cells $(47,48)$. By contrast, IL-19, IL-20 and IL-24 are produced primarily by macrophages $(49,50)$. A number of DNase HS sites have been identified within $30 \mathrm{~kb}$ of murine $I l 10$, some of which can act as enhancers (50), but their role in the regulation of $I l 10$, whether any act on neighboring genes, and the 3-dimensional architecture of this locus are unknown. In human CD4 T cells, the ILIO gene is bracketed by strong CTCF binding sites (13••), perhaps allowing it to be regulated independently of neighboring family members. Another example is the locus containing ILI2rb2 and IL23r. IL-12 is a cytokine critical for Th1 polarization, while IL-23 has been shown to augment the Th17 response. Receptors for these cytokines share a common subunit IL-12R $\beta 1$, thus responsiveness of a $\mathrm{T}$ cell to one or the other is determined by which gene is transcribed from the $I L 23 r / I l 12 r b 2$ locus, raising the possibility that their clustering facilitates alternative expression through competitive utilization of a nearby regulatory element.

\section{Trans-regulation through intrachromosomal interactions?}

While intrachromosomal interactions appear to be common, genome-wide $4 \mathrm{C}$ analyses (Box 1) show that interactions between regions on different chromosomes also occur $(51 \bullet, 52 \cdot, 53)$. In principle, looping that approximates regions from different chromosomes could allow the transcription of a gene on one chromosome to be regulated in trans by regulatory elements from another. However, such trans-regulation has been tested for only a few intrachromosomal interactions, and the results do not always suggest that interactions denote function. For example, each olfactory neuron expresses only one of many olfactory receptor genes scattered across the genome, and expression correlates strongly with spatial approximation of the expressed gene to the $\mathrm{H}$ enhancer on chromosome 14, suggesting that approximation permits trans-regulation by this enhancer (54). However, disruption of the $\mathrm{H}$ enhancer only affected expression of nearby olfactory receptor genes on chromosome 14 (55). Better evidence for trans-regulation was obtained from studies in naïve CD4 T cells. The Ifng promoter on murine chromosome 10 was reported to interact in trans with the $I l 5$ promoter, Rad50 promoter and Th2 LCR RHS6 on murine chromosome 11 (56). Mutation of RHS7 within the Th2 LCR 
(Figure 2) not only abrogated these interactions, but also led to delayed Ifng and decreased Il5 expression when naïve T cells were differentiated under Th1 and Th2 conditions, respectively (56). These results suggest that proximity in naïve T cells helps to poise both loci. When naïve T cells adopt the Th2 fate, intrachromosomal interactions within the Th2 and Th1 loci increase and interchromosomal interactions between these loci appear to be abolished, leading to the proposal that this switch contributes to lineage specification.

\section{Conclusions}

The availability of complete genome sequences and new experimental tools has allowed candidate gene regulatory elements to be identified and their function to be inferred on a genome-wide scale and at high resolution. Similarly, chromatin conformation capture assays (3C-5C) have been scaled to map all interactions within a defined region or the interactions of one region with the rest of the genome, while advances in microscopy have refined the resolution of FISH, permitting interactions identified by 3-5C to be independently validated (Box 1). These innovations can be expected to provide us with a comprehensive knowledge of candidate gene regulatory elements and their interactions in T cell subsets and other cell types of interest in the near future. A challenge thereafter will be to extend these findings, which will be derived from bulk populations, to understand the dynamics of TF interactions with regulatory elements, chromatin modifications and chromatin looping in individual cells. Studies in the Th2 locus have provided evidence that TFs we consider Th2 lineage-specific (STAT6 and GATA-3) bring together distal regulatory elements to facilitate Th2 gene expression, but what role do the Th1-specific TFs T-bet and STAT4 play in the interactions of critical cis-regulatory elements with the Ifng promoter? Similarly, trans-interactions between the Th2 and Ifng loci have been reported in naïve T cells, but confirmation of these findings and elucidation of the mechanisms and regulatory proteins involved are yet needed. And whether looping-induced physical interactions between regulatory elements are the driving force behind changes in gene expression or are more often merely coincidental due to the spatial constraints of the nucleus remains to be seen.

\section{Box 1}

\section{Approaches to Identify or Infer the Presence of Gene Regulatory Regions and to Characterize their Status and Interactions}

This box describes complementary experimental approaches by which to detect candidate gene regulatory elements. By comparing findings in cell types that do or do not express the gene(s) of interest (e.g., Th1 vs. Th2 cells) or that do or do not have the potential to do so (e.g., naïve CD4 T cells vs. fibroblasts) element detection is enhanced and, in some cases, the function of elements can be imputed (Figure 1), thus helping to prioritize and to inform the design of experiments to test function directly.

\section{Chromatin immunoprecipitation (ChIP)}

This assay detects modified histones, transcription factors and other regulatory proteins by immunoprecipitation followed by analysis of the associated DNA; provides information regarding the location of regulatory elements, genes/gene loci, locus boundaries and their activity in that cell type.

ChIP-PCR and ChIP-qPCR - Focused assessment of candidate sequences/regions by PCR or quantitative real-time PCR.

ChIP-chip - DNA is amplified and hybridized to a focused or genome-wide microarray (with repetitive regions omitted). More comprehensive than PCR-based approaches; technical and statistical/threshold issues must be carefully considered; may be somewhat less sensitive and have a narrower dynamic range than qPCR $(15,57)$. 
ChIP-seq - DNA is amplified, size selected and the abundance and sequence of short tags determined by high-throughput sequencing until novel tag discovery reaches/ approaches saturation (typically $>10^{7}$ tag sequences); more quantitative than ChIP-chip with high dynamic range; limited polymorphisms between individuals/strains do not interfere with detection or quantitation; allele-specific differences can be detected; if sequencing does not reach saturation, may fail to detect more weakly associated sequences $(13 \bullet \bullet, 16 \bullet)$.

\section{MethylDIP-chip or MethylDIP-seq}

This assay assesses DNA cytosine methylation. DNA methylation of regulatory elements, particularly at promoters and the proximal transcribed regions, typically inhibits transcription. Cytosine methylation is assessed as for ChIP-chip or ChIP-Seq using an antibody specific for methylated cytosine. Allows genomewide semi-quantitative assessment of DNA methylation; this approach may underestimate or fail to detect $\mathrm{CpG}$ methylation in regions in which the density of CpGs is low; resolution is less than that of sequencing of bisulfite-modified DNA (58).

\section{DNase I hypersensitive site detection (HS)}

HS sites are regions where the density of nucleosomes is reduced or the association of DNA with nucleosomes is otherwise altered so that the DNA is more sensitive to digestion with DNaseI (and/or other nucleases) than surrounding regions. HS sites are present at all or nearly all gene regulatory elements, including promoters, enhancers, silencers, boundary elements, and locus control regions, that are active or poised for activity in the cell type evaluated.

Southern blot analysis - Yields approximate location and semi-quantitative estimate of the degree of hypersensitivity.

DNase-qPCR - Focused, high resolution ( 250bp), quantitative detection of HS sites.

DNase-chip or DNase-seq - Approach, principals, output, resolution and quantitation analogous to ChIP-chip or ChIP-Seq $(19 \bullet \bullet, 59,60)$.

\section{Chromatin Conformation Capture $(52 \bullet, 61)$}

These assays assess the physical proximity between DNA sequences as they occur in the nucleus. As noted in the text, distal regulatory elements are often approximated to the genes they regulate and active or repressed genes are often approximated to each other at transcription factories or in heterochromatin, respectively.

3C - chromatin confirmation capture - Focused analysis of interactions between one DNA fragment (the anchor) and a few other regions of interest with detection by PCR or qPCR.

4C - circular chromatin confirmation capture - Allows genome wide screening for DNA fragments interacting with a specific (anchor) DNA fragment. 3C is followed by inverse PCR and detection of interacting DNA fragments by hybridization to tiling microarrays or high-throughput sequencing. Most useful for detecting interactions with regions $\geq 5 \mathrm{MB}$ from the anchor fragment, with specific interactions difficult to resolve from background for regions $<5 \mathrm{MB}$ away.

5C - chromatin conformation capture carbon copy - Multiplexed analysis of hundreds/ thousands of DNA fragments within a genomic region of interest followed with detection as done for $4 \mathrm{C}$.

Chip-loop - Chromatin immunoprecipitation is used first to select for sequences associated with a specific protein after which $3 \mathrm{C}$ is performed. 


\section{FISH (fluorescence in situ hybrization)}

This assay assesses the sub-nuclear location of genes/loci/chromosome territories and physical proximity of two or more genomic regions to each other. The information is complementary to that obtained by $3-5 \mathrm{C}$; resolution of sequences separated by as little as $90 \mathrm{~kb}$ of linear DNA can be achieved (62).

3D-FISH - FISH is performed on cells processed in a manner that the 3-dimensional structure of the nucleus is preserved, with or without 3-D reconstruction of images obtained by confocal fluorescence microscopy.

Cryo-FISH - A variation of 3-D in which 100-200 nm cryosections are made of paraformaldehyde fixed cells, which improves resolution by removing out of focus light that would otherwise be reflected by objects outside the section in the $\mathrm{z}$ axis (63).

Immuno-FISH - Immunofluorescence and FISH are done together to detect protein colocalization with specific genes/loci/chromosomes.

\section{Acknowledgements}

Work in the authors' laboratories was supported by the National Institutes of Health (T32-AI07411, R01-AI071272, N01-AI40069, R01-HD18184 - ER and CBW) the Medical Research Council, UK (MM).

\section{References}

1. Djuretic IM, Levanon D, Negreanu V, Groner Y, Rao A, Ansel KM. Transcription factors T-bet and Runx3 cooperate to activate Ifng and silence Il4 in T helper type 1 cells. Nat Immunol 2007;8:145153. [PubMed: 17195845]

2. Naoe Y, Setoguchi R, Akiyama K, Muroi S, Kuroda M, Hatam F, Littman DR, Taniuchi I. Repression of interleukin-4 in T helper type 1 cells by Runx/Cbf beta binding to the I14 silencer. J Exp Med 2007;204:1749-1755. [PubMed: 17646405]

3. Yang XO, Pappu BP, Nurieva R, Akimzhanov A, Kang HS, Chung Y, Ma L, Shah B, Panopoulos AD, Schluns KS, Watowich SS, Tian Q, Jetten AM, Dong C. T helper 17 lineage differentiation is programmed by orphan nuclear receptors ROR alpha and ROR gamma. Immunity 2008;28:29-39. [PubMed: 18164222]

4. Agarwal S, Rao A. Long-range transcriptional regulation of cytokine gene expression. Curr Opin Immunol 1998;10:345-352. [PubMed: 9638372]

5. Ogbourne S, Antalis TM. Transcriptional control and the role of silencers in transcriptional regulation in eukaryotes. Biochem J 1998;331(Pt 1):1-14. [PubMed: 9512455]

6. Li Q, Peterson KR, Fang X, Stamatoyannopoulos G. Locus control regions. Blood 2002;100:30773086. [PubMed: 12384402]

7. Gaszner M, Felsenfeld G. Insulators: exploiting transcriptional and epigenetic mechanisms. Nat Rev Genet 2006;7:703-713. [PubMed: 16909129]

8. Galande S, Purbey PK, Notani D, Kumar PP. The third dimension of gene regulation: organization of dynamic chromatin loopscape by SATB1. Curr Opin Genet Dev 2007;17:408-414. [PubMed: 17913490]

9. Lee GR, Kim ST, Spilianakis CG, Fields PE, Flavell RA. T helper cell differentiation: regulation by cis elements and epigenetics. Immunity 2006;24:369-379. [PubMed: 16618596]

10. Nardone J, Lee DU, Ansel KM, Rao A. Bioinformatics for the 'bench biologist': how to find regulatory regions in genomic DNA. Nat Immunol 2004;5:768-774. [PubMed: 15282556]

11 • Birney E, Stamatoyannopoulos JA, Dutta A, Guigo R, Gingeras TR, Margulies EH, Weng Z, Snyder M, Dermitzakis ET, Thurman RE, et al. Identification and analysis of functional elements in $1 \%$ of the human genome by the ENCODE pilot project. Nature 2007;447:799-816. [PubMed: 17571346] The ENCODE consortium applied a suite of approaches to map gene regulatory elements in several human cell lines within selected regions representing $\sim 1 \%$ of the genome, including the Th2 cytokine locus. 
12. Dorschner MO, Hawrylycz M, Humbert R, Wallace JC, Shafer A, Kawamoto J, Mack J, Hall R, Goldy J, Sabo PJ, Kohli A, Li Q, McArthur M, Stamatoyannopoulos JA. High-throughput localization of functional elements by quantitative chromatin profiling. Nat Methods 2004;1:219225. [PubMed: 15782197]

13••. Barski A, Cuddapah S, Cui K, Roh TY, Schones DE, Wang Z, Wei G, Chepelev I, Zhao K. Highresolution profiling of histone methylations in the human genome. Cell 2007;129:823-837. [PubMed: 17512414]A comprehensive, genome-wide map of putative gene regulatory elements in total resting human CD4 T cells as identified by ChIP-seq detection of their associated histones, histone modifications and regulatory proteins.

14. Guenther MG, Levine SS, Boyer LA, Jaenisch R, Young RA. A chromatin landmark and transcription initiation at most promoters in human cells. Cell 2007;130:77-88. [PubMed: 17632057]

15. Heintzman ND, Stuart RK, Hon G, Fu Y, Ching CW, Hawkins RD, Barrera LO, Van Calcar S, Qu C, Ching KA, Wang W, Weng Z, Green RD, Crawford GE, Ren B. Distinct and predictive chromatin signatures of transcriptional promoters and enhancers in the human genome. Nat Genet 2007;39:311318. [PubMed: 17277777]

16•. Mikkelsen TS, Ku M, Jaffe DB, Issac B, Lieberman E, Giannoukos G, Alvarez P, Brockman W, Kim TK, Koche RP, Lee W, Mendenhall E, O'Donovan A, Presser A, Russ C, Xie X, Meissner A, Wernig M, Jaenisch R, Nusbaum C, Lander ES, Bernstein BE. Genome-wide maps of chromatin state in pluripotent and lineage-committed cells. Nature 2007;448:553-560. [PubMed: 17603471] A comprehensive, genome-wide map of histone modifications associated with active, poised, silenced genes and novel transcripts obtained through ChIP-seq analysis of mouse embryonic stem cells, fibroblasts and neuronal stem cells.

17. Pan G, Tian S, Nie J, Yang C, Ruotti V, Wei H, Jonsdottir GA, Stewart R, Thomson JA. Wholegenome analysis of histone $\mathrm{H} 3$ lysine 4 and lysine 27 methylation in human embryonic stem cells. Cell Stem Cell 2007;1:299-312. [PubMed: 18371364]

18. Zhao XD, Han X, Chew JL, Liu J, Chiu KP, Choo A, Orlov YL, Sung WK, Shahab A, Kuznetsov VA, Bourque G, Oh S, Ruan Y, Ng HH, Wei CL. Whole-genome mapping of histone H3Lys4 and 27 trimethylations reveals distinct genomic compartments in human embryonic stem cells. Cell Stem Cell 2007;1:286-298. [PubMed: 18371363]

19••. Boyle AP, Davis S, Shulha HP, Meltzer P, Margulies EH, Weng Z, Furey TS, Crawford GE. Highresolution mapping and characterization of open chromatin across the genome. Cell 2008;132:311322. [PubMed: 18243105]A comprehensive, genome-wide map of DNase hypersensitive sites in total resting human CD4 T cells obtained using DNase-seq and DNase-chip and compared to the histone modifications identified in this cell type by Barski et al (ref 13).

20. Vermeulen M, Mulder KW, Denissov S, Pijnappel WW, van Schaik FM, Varier RA, Baltissen MP, Stunnenberg HG, Mann M, Timmers HT. Selective anchoring of TFIID to nucleosomes by trimethylation of histone H3 lysine 4. Cell 2007;131:58-69. [PubMed: 17884155]

21. Sims RJ 3rd, Millhouse S, Chen CF, Lewis BA, Erdjument-Bromage H, Tempst P, Manley JL, Reinberg D. Recognition of Trimethylated Histone H3 Lysine 4 Facilitates the Recruitment of Transcription Postinitiation Factors and Pre-mRNA Splicing. Mol Cell 2007;28:665-676. [PubMed: 18042460]

22. Ruthenburg AJ, Allis CD, Wysocka J. Methylation of lysine 4 on histone H3: intricacy of writing and reading a single epigenetic mark. Mol Cell 2007;25:15-30. [PubMed: 17218268]

23. Kouzarides T. Chromatin modifications and their function. Cell 2007;128:693-705. [PubMed: 17320507]

24. Berger SL. The complex language of chromatin regulation during transcription. Nature 2007;447:407-412. [PubMed: 17522673]

25. Azuara V, Perry P, Sauer S, Spivakov M, Jorgensen HF, John RM, Gouti M, Casanova M, Warnes G, Merkenschlager M, Fisher AG. Chromatin signatures of pluripotent cell lines. Nat Cell Biol 2006;8:532-538. [PubMed: 16570078]

26•. Parelho V, Hadjur S, Spivakov M, Leleu M, Sauer S, Gregson HC, Jarmuz A, Canzonetta C, Webster Z, Nesterova T, Cobb BS, Yokomori K, Dillon N, Aragon L, Fisher AG, Merkenschlager M. Cohesins functionally associate with CTCF on mammalian chromosome arms. Cell 2008; 132:422433. [PubMed: 18237772]Demonstrates in $\mathrm{T}$ and $\mathrm{B}$ cell lines and in thymocytes that cohesin colocalizes with CTCF in the genome. In experimental settings, cohesins contribute to the insulator 
function of CTCF, but this function remains to be demonstrated for endogenous sites. Cohesin and CTCF sites are also found within genes, including the Ifng gene, where they do not preclude active transcription and chromatin remodeling.

27•. Wendt KS, Yoshida K, Itoh T, Bando M, Koch B, Schirghuber E, Tsutsumi S, Nagae G, Ishihara K, Mishiro T, Yahata K, Imamoto F, Aburatani H, Nakao M, Imamoto N, Maeshima K, Shirahige K, Peters JM. Cohesin mediates transcriptional insulation by CCCTC-binding factor. Nature 2008;451:796-801. [PubMed: 18235444]Reports findings similar to ref 25, but did not include studies in lymphocytes.

28. Koyanagi M, Baguet A, Martens J, Margueron R, Jenuwein T, Bix M. EZH2 and histone 3 trimethyl lysine 27 associated with Il4 and Il13 gene silencing in Th1 cells. J Biol Chem 2005;280:3147031477. [PubMed: 16009709]

29. Kosak ST, Scalzo D, Alworth SV, Li F, Palmer S, Enver T, Lee JS, Groudine M. Coordinate gene regulation during hematopoiesis is related to genomic organization. PLoS Biol 2007;5:e309. [PubMed: 18031200]

30. Singer GA, Lloyd AT, Huminiecki LB, Wolfe KH. Clusters of co-expressed genes in mammalian genomes are conserved by natural selection. Mol Biol Evol 2005;22:767-775. [PubMed: 15574806]

31. Sproul D, Gilbert N, Bickmore WA. The role of chromatin structure in regulating the expression of clustered genes. Nat Rev Genet 2005;6:775-781. [PubMed: 16160692]

32. Ansel KM, Djuretic I, Tanasa B, Rao A. Regulation of Th2 differentiation and Il4 locus accessibility. Annu Rev Immunol 2006;24:607-656. [PubMed: 16551261]

33. Spilianakis CG, Flavell RA. Long-range intrachromosomal interactions in the Thelper type 2 cytokine locus. Nat Immunol 2004;5:1017-1027. [PubMed: 15378057]

34- Cai S, Lee CC, Kohwi-Shigematsu T. SATB1 packages densely looped, transcriptionally active chromatin for coordinated expression of cytokine genes. Nat Genet 2006;38:1278-1288. [PubMed: 17057718]Demonstrates activation-induced, SATB1-dependent chromatin looping in the Th2 cytokine locus and its importance in Th2 cytokine expression using ChIP, ChIP-loop, and siRNAmediated knockdown.

35. Chang S, Aune TM. Dynamic changes in histone-methylation 'marks' across the locus encoding interferon-gamma during the differentiation of T helper type 2 cells. Nat Immunol 2007;8:723-731. [PubMed: 17546034]

36. Hatton RD, Harrington LE, Luther RJ, Wakefield T, Janowski KM, Oliver JR, Lallone RL, Murphy $\mathrm{KM}$, Weaver CT. A distal conserved sequence element controls Ifng gene expression by $\mathrm{T}$ cell and NK cells. Immunity. 2006

37. Lee DU, Avni O, Chen L, Rao A. A distal enhancer in the interferon-gamma (IFN-gamma) locus revealed by genome sequence comparison. J Biol Chem 2004;279:4802-4810. [PubMed: 14607827]

38• Schoenborn JR, Dorschner MO, Sekimata M, Santer DM, Shnyreva M, Fitzpatrick DR, Stamatoyannopoulos JA, Wilson CB. Comprehensive epigenetic profiling identifies multiple distal regulatory elements directing transcription of the gene encoding interferon-gamma. Nat Immunol 2007;8:732-742. [PubMed: 17546033]Describes species-specific differences in the Ifng locus and detection of multiple distal regulatory elements in this locus through comprehensive, highresolution DNase HS site, histone modification, DNA methylation and functional analyses.

39. Shnyreva M, Weaver WM, Blanchette M, Taylor SL, Tompa M, Fitzpatrick DR, Wilson CB. Evolutionarily conserved sequence elements that positively regulate IFN-gamma expression in $\mathrm{T}$ cells. Proc Natl Acad Sci U S A 2004;101:12622-12627. [PubMed: 15304658]

40. Lund R, Ahlfors H, Kainonen E, Lahesmaa AM, Dixon C, Lahesmaa R. Identification of genes involved in the initiation of human Th1 or Th2 cell commitment. Eur J Immunol 2005;35:3307-3319. [PubMed: 16220538]

41. Acosta-Rodriguez EV, Napolitani G, Lanzavecchia A, Sallusto F. Interleukins 1beta and 6 but not transforming growth factor-beta are essential for the differentiation of interleukin 17-producing human T helper cells. Nat Immunol 2007;8:942-949. [PubMed: 17676045]

42. Acosta-Rodriguez EV, Rivino L, Geginat J, Jarrossay D, Gattorno M, Lanzavecchia A, Sallusto F, Napolitani G. Surface phenotype and antigenic specificity of human interleukin 17-producing T helper memory cells. Nat Immunol 2007;8:639-646. [PubMed: 17486092] 
43. Liang SC, Tan XY, Luxenberg DP, Karim R, Dunussi-Joannopoulos K, Collins M, Fouser LA. Interleukin (IL)-22 and IL-17 are coexpressed by Th17 cells and cooperatively enhance expression of antimicrobial peptides. J Exp Med 2006;203:2271-2279. [PubMed: 16982811]

44. Wolk K, Kunz S, Asadullah K, Sabat R. Cutting edge: immune cells as sources and targets of the IL-10 family members? J Immunol 2002;168:5397-5402. [PubMed: 12023331]

45. Zheng Y, Danilenko DM, Valdez P, Kasman I, Eastham-Anderson J, Wu J, Ouyang W. Interleukin-22, a $\mathrm{T}(\mathrm{H}) 17$ cytokine, mediates IL-23-induced dermal inflammation and acanthosis. Nature 2007;445:648-651. [PubMed: 17187052]

46. Wilson NJ, Boniface K, Chan JR, McKenzie BS, Blumenschein WM, Mattson JD, Basham B, Smith K, Chen T, Morel F, Lecron JC, Kastelein RA, Cua DJ, McClanahan TK, Bowman EP, de Waal Malefyt R. Development, cytokine profile and function of human interleukin 17-producing helper T cells. Nat Immunol 2007;8:950-957. [PubMed: 17676044]

47. McGeachy MJ, Bak-Jensen KS, Chen Y, Tato CM, Blumenschein W, McClanahan T, Cua DJ. TGFbeta and IL- 6 drive the production of IL-17 and IL-10 by T cells and restrain T(H)-17 cell-mediated pathology. Nat Immunol 2007;8:1390-1397. [PubMed: 17994024]

48. O'Garra A, Vieira P. T(H)1 cells control themselves by producing interleukin-10. Nat Rev Immunol 2007;7:425-428. [PubMed: 17525751]

49. Kunz S, Wolk K, Witte E, Witte K, Doecke WD, Volk HD, Sterry W, Asadullah K, Sabat R. Interleukin (IL)-19, IL-20 and IL-24 are produced by and act on keratinocytes and are distinct from classical ILs. Exp Dermatol 2006;15:991-1004. [PubMed: 17083366]

50. Jones EA, Flavell RA. Distal enhancer elements transcribe intergenic RNA in the IL-10 family gene cluster. J Immunol 2005;175:7437-7446. [PubMed: 16301651]

51 • Simonis M, Klous P, Splinter E, Moshkin Y, Willemsen R, de Wit E, van Steensel B, de Laat W. Nuclear organization of active and inactive chromatin domains uncovered by chromosome conformation capture-on-chip (4C). Nat Genet 2006;38:1348-1354. [PubMed: 17033623] Demonstrates using $4 \mathrm{C}$ that interchromosomal $c$ is interactions between distant loci $(>5-10 \mathrm{MB}$ apart) on the same chromosome are relatively common, though less so than cis interactions of more proximate regions, and that intrachromosomal trans interactions are relatively rare.

52. Simonis M, Kooren J, de Laat W. An evaluation of 3C-based methods to capture DNA interactions. Nat Methods 2007;4:895-901. [PubMed: 17971780]Critical comparison of different chromatin conformation capture assays and their purposes, strengths and weaknesses.

53. Zhao Z, Tavoosidana G, Sjolinder M, Gondor A, Mariano P, Wang S, Kanduri C, Lezcano M, Sandhu KS, Singh U, Pant V, Tiwari V, Kurukuti S, Ohlsson R. Circular chromosome conformation capture (4C) uncovers extensive networks of epigenetically regulated intra- and interchromosomal interactions. Nat Genet 2006;38:1341-1347. [PubMed: 17033624]

54. Lomvardas S, Barnea G, Pisapia DJ, Mendelsohn M, Kirkland J, Axel R. Interchromosomal interactions and olfactory receptor choice. Cell 2006;126:403-413. [PubMed: 16873069]

55. Fuss SH, Omura M, Mombaerts P. Local and cis effects of the H element on expression of odorant receptor genes in mouse. Cell 2007;130:373-384. [PubMed: 17662950]

56. Spilianakis CG, Lalioti MD, Town T, Lee GR, Flavell RA. Interchromosomal associations between alternatively expressed loci. Nature 2005;435:637-645. [PubMed: 15880101]

57. Weinmann AS. Novel ChIP-based strategies to uncover transcription factor target genes in the immune system. Nat Rev Immunol 2004;4:381-386. [PubMed: 15122203]

58. Weber M, Hellmann I, Stadler MB, Ramos L, Paabo S, Rebhan M, Schubeler D. Distribution, silencing potential and evolutionary impact of promoter DNA methylation in the human genome. Nat Genet 2007;39:457-466. [PubMed: 17334365]

59. Sabo PJ, Humbert R, Hawrylycz M, Wallace JC, Dorschner MO, McArthur M, Stamatoyannopoulos JA. Genome-wide identification of DNaseI hypersensitive sites using active chromatin sequence libraries. Proc Natl Acad Sci U S A 2004;101:4537-4542. [PubMed: 15070753]

60. Sabo PJ, Kuehn MS, Thurman R, Johnson BE, Johnson EM, Cao H, Yu M, Rosenzweig E, Goldy J, Haydock A, Weaver M, Shafer A, Lee K, Neri F, Humbert R, Singer MA, Richmond TA, Dorschner MO, McArthur M, Hawrylycz M, Green RD, Navas PA, Noble WS, Stamatoyannopoulos JA. Genome-scale mapping of DNase I sensitivity in vivo using tiling DNA microarrays. Nat Methods 2006;3:511-518. [PubMed: 16791208] 
61. Dekker J. The three 'C' s of chromosome conformation capture: controls, controls, controls. Nat Methods 2006;3:17-21. [PubMed: 16369547]

62. Chambeyron S, Bickmore WA. Chromatin decondensation and nuclear reorganization of the HoxB locus upon induction of transcription. Genes Dev 2004;18:1119-1130. [PubMed: 15155579]

63. Branco MR, Pombo A. Intermingling of chromosome territories in interphase suggests role in translocations and transcription-dependent associations. PLoS Biol 2006;4:e138. [PubMed: 16623600]

64. Schoenborn JR, Wilson CB. Regulation of interferon-gamma during innate and adaptive immune responses. Adv Immunol 2007;96:41-101. [PubMed: 17981204] 


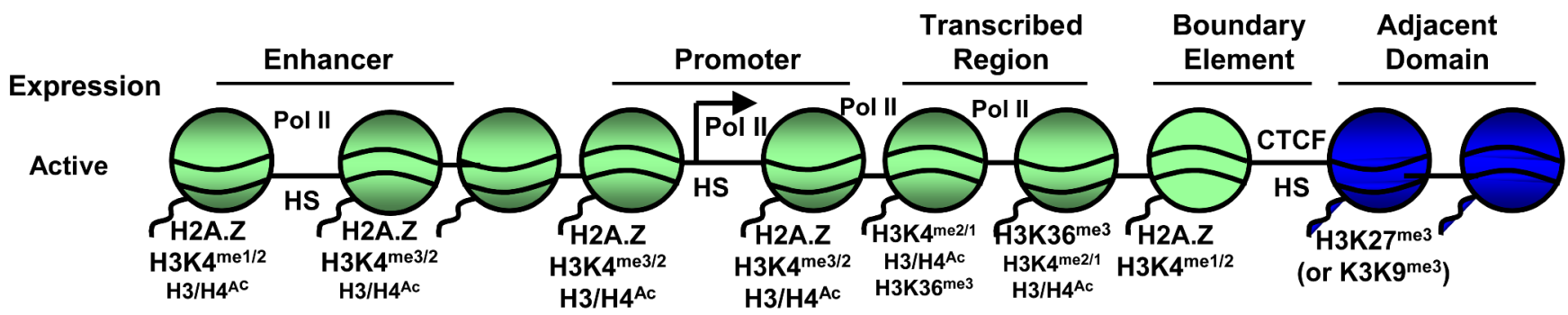

Primed-

Recently

Active

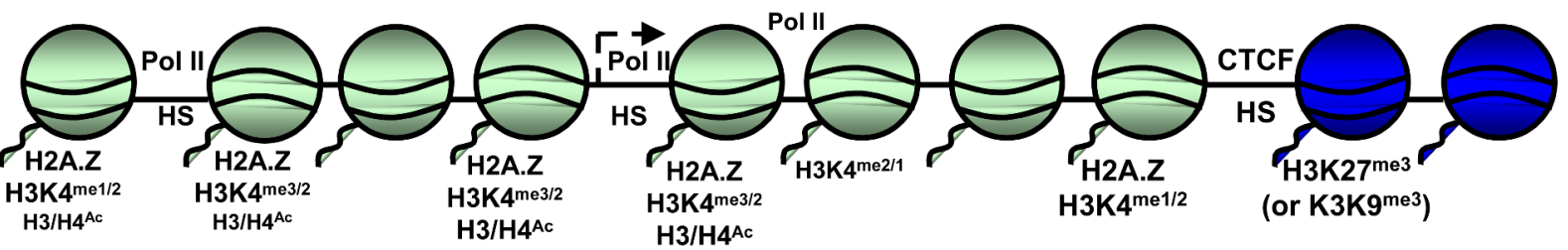

Poised

'Bivalent'

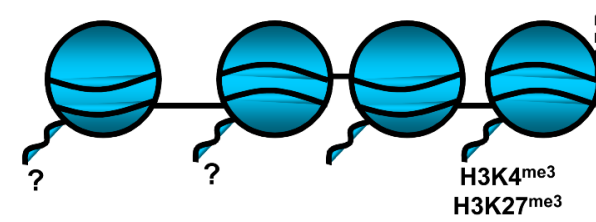

$\mathrm{H} 3 / \mathrm{H} 4^{A c}$

H3K4 ${ }^{\mathrm{me} 1 / 2}$

(or K3K9me3)

Poised

'Null'

Silenced

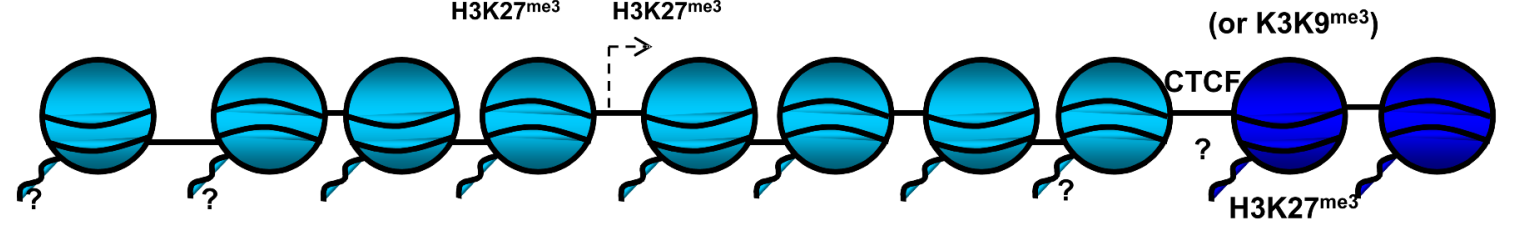

(or K3K ${ }^{\mathrm{me} 3}$ )

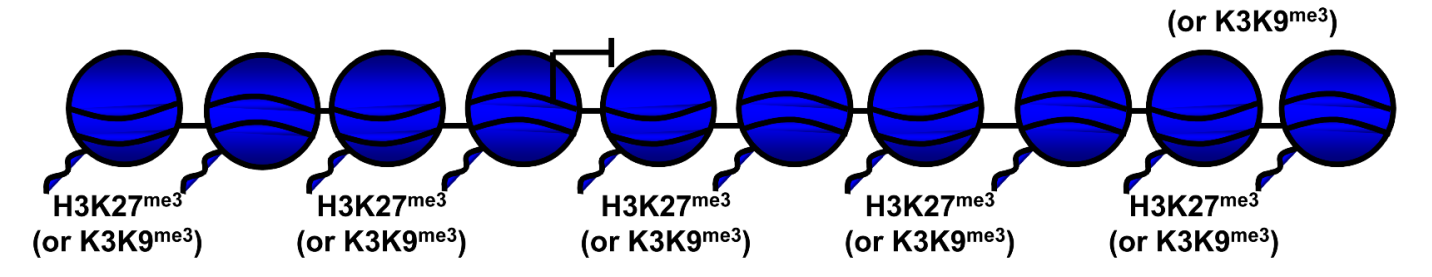

Figure 1.

Typical patterns of histones/histone modifications, DNase hypersensitive sites (HS), RNA polymerase II (Pol II) and CTCF binding to genes and their regulatory elements. A gene, its regulatory elements and surrounding chromatin domain are shown on the left with nucleosomes depicted as balls color coded to gene activity, DNA shown as a black line, and H3/H4 tails shown as waved lines extending to the lower left of each nucleosome. Two nucleosomes of an adjacent inactive domain are to the right with a boundary element separating the two domains. Font size denotes relative enrichment for the indicated histone modifications, histone H2A.Z, Pol II and CTCF. Question marks indicate unknown or uncertain. Active genes = ongoing transcription. Primed-Recently Active genes = recent but not active transcription. Poised = inactive but poised for future activation or silencing; Poised 'bivalent' have $\mathrm{H} 3 \mathrm{~K} 4{ }^{\mathrm{me} 3}$ and $\mathrm{H} 3 \mathrm{~K} 27^{\mathrm{me} 3}$ marks on nearby nucleosomes in their promoters; Poised 'null' gene promoters lack these marks. Data are derived from $(11 \bullet, 13 \bullet \bullet, 14-15,16 \bullet, 18,19 \bullet \bullet)$. 

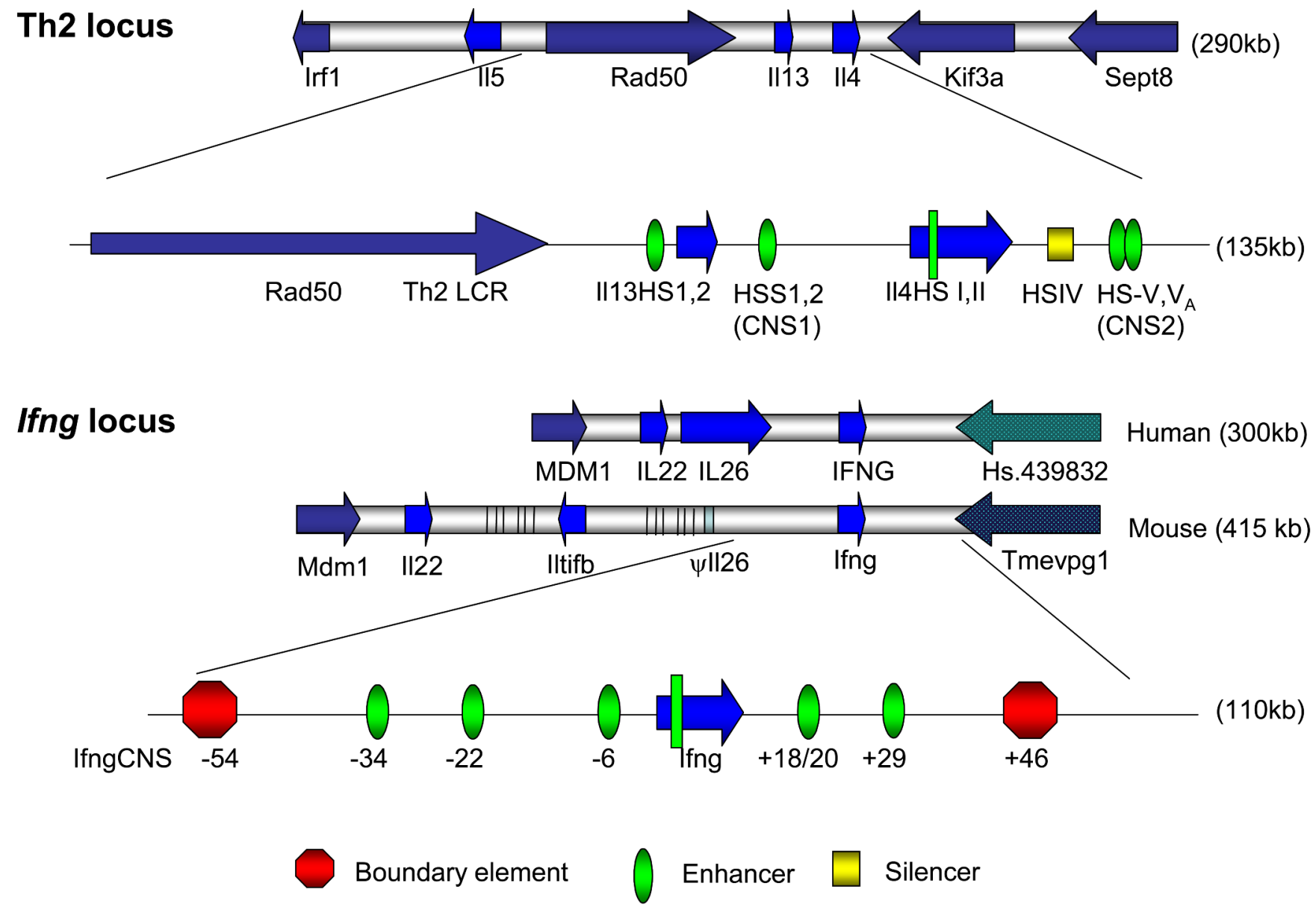

Figure 2.

Distal regulatory elements in the Th2 and Ifng loci. The Th2 cytokine locus is shown at the top; its synteny is conserved in humans, mice and other mammals. A portion of this locus is expanded to demonstrate known regulatory elements, including the locus control region (LCR) in the 3' end of the Rad50 gene, several enhancers and the Il4 silencer (reviewed in (32). The IFNG (human) and Ifng (mouse) loci are shown below the Th2 locus. The relationships between IFNG and its neighboring genes in humans are conserved in all mammalian species for which data is available with the exception of rats and mice. Structural rearrangements in rodents resulted in the deletion of the gene encoding IL-26 ( $\psi$ I126, denotes remaining sequences homologous to IL26). In some strains of mice, including C57BL/6 whose genome has been fully sequenced, this locus contains an inverted duplication of Il22, known as Iltifb, flanked by six tandem repeats of a highly conserved repetitive element. Downstream of IFNG/Ifng there are no known coding transcripts for $\sim 500 \mathrm{~kb}$, but a non-coding anti-sense transcript has been annotated in humans (Hs. 439832) and in mouse (Tmevpg1), terminating 137 and $\sim 57 \mathrm{~kb} 3^{\prime}$ of IFNG and Ifng, respectively. In the expanded portion of this locus, distal regulatory elements as defined in the mouse are shown (reviewed in (64)). Arrows indicate the direction of gene transcription; the approximate size of each region is shown to the right; symbols at the bottom provide a key indicating the function of elements shown above. 